\title{
Overlying Strata Movement and Abutment Pressure Evolution Process of Fully Mechanized Top Coal Caving Mining in Extra Thick Coal Seam
}

\author{
Yongqiang Zhao, ${ }^{1}$ Yingming Yang $\mathbb{D}^{1}$ Xiaobin Li $\mathbb{D},{ }^{2}$ and Zhiqi Wang $\mathbb{D}^{3}$ \\ ${ }^{1}$ State Key Laboratory of Water Resource Protection and Utilization in Coal Mining, Beijing 102209, China \\ ${ }^{2}$ School of Energy and Mining Engineering, China University of Mining and Technology (Beijing), Beijing 100083, China \\ ${ }^{3}$ College of Energy and Mining Engineering, Shandong University of Science and Technology, Qingdao 266590, China
}

Correspondence should be addressed to Yingming Yang; yangym1988@163.com, Xiaobin Li; 1xb162197@126.com, and Zhiqi Wang; 981477881@qq.com

Received 7 September 2021; Accepted 10 November 2021; Published 25 November 2021

Academic Editor: Zhengyang Song

Copyright (c) 2021 Yongqiang Zhao et al. This is an open access article distributed under the Creative Commons Attribution License, which permits unrestricted use, distribution, and reproduction in any medium, provided the original work is properly cited.

\begin{abstract}
Taken overlying strata of fully mechanized top coal caving mining (FMTCCM) in $15 \mathrm{~m}$ extra thick coal seam as the research object, the comprehensive research methods such as field investigation, theoretical calculation, and numerical analysis are used to systematically analyze. During the mining of extra thick coal seam, the overlying strata form the structure of lower cantilever beam and upper hinged rock beam. The downward transmission caused by the interaction of this combined structure is the fundamental reason for the strong periodic ground pressure behavior of working face and roadway blow. The movement process of overlying strata movement is divided into four stages, and dynamic distribution characteristics of lateral abutment pressure in different stages are obtained. It is considered that the gob side roadway can be in a relatively stable overburden structure and stress environment during the stable stage of abutment pressure. The distribution range of the internal and external stress fields is determined, which provides a theoretical basis for the reasonable roadway layout. At last, the fracture position and abutment pressure evolution process of overlying strata along the goaf side of the extra thick coal seam are further verified by drilling stress measurement.
\end{abstract}

\section{Introduction}

China is rich in thick coal seam and extra thick coal seam, whose reserves and production account for about $45 \%$ of the total reserves. In recent years, extra thick and thick coal seams have become the main coal seam in China. During the mining of extra thick coal seam, the ground pressure behavior is severe and the peak value of abutment pressure is large. During the mining of the upper section working face, along the advancing direction of the vertical working face, the overlying strata will break, rotate, and sink successively after the first weighting, and the basic roof will be broken periodically to form a stable structure [1-3]. The distribution of lateral abutment pressure is directly related to the occurrence state of the overlying basic roof rock and the macrostructure formed after fracture $[4,5]$.

At present, many studies have been carried on the overburden activity characteristics and abutment pressure evolution law. Zhu [6] put forward the point of view that the "triangle hanging plate" structure is formed in the end of working face and established a mechanical model of the stope roof structure. It is considered that the shape size and movement characteristics of the overlying hanging plate structure are closely related to the mine pressure behavior law of driving along the goaf. Song et al. $[7,8]$ developed a mechanical model of overlying strata of a roadway driving along the goaf, divided the lateral basic roof fracture position into the internal and external stress fields before and after, 
and considered that digging roadway within the scope of the internal stress field can effectively avoid major accidents. On the contrary, when the roadway is excavated within the scope of the external stress field, the stability of roadway is poor and maintenance is difficult. Yu et al. [9] think that after the working face is mined, the rupture, rotation, and subsidence of the arc triangle block above the goaf force the lateral abutment pressure to transfer to the deep part of the solid coal, and a stress reduction area will be formed at the edge of the goaf. The serious stress disaster can be avoided by driving along the goaf in the lower stress area, and a large number of field tests have been conducted underground. Ma et al. [10] conducted field measurement and analysis on the ground pressure of some fully mechanized top coal caving faces and mining roadways and found that the mining and caving ratio of the working face have an effect on the distribution characteristics of lateral abutment pressure. Meanwhile, the peak point of lateral abutment pressure moves far away with the increase of caving ratio, which is favorable for driving roadway along the goaf with a narrow coal pillar. Wang et al. [11] obtained the dynamic evolution process of the lateral abutment pressure and microseismic activity through mine pressure observation and considered that the vertical stress trend of lateral coal seam in the goaf presented different stage characteristics. The stress and elastic-plastic evolution law of coal seam in each stage and interval were obtained through the measured data. Taking the $8.5 \mathrm{~m}$ mining height fully mechanized working face of Shangwan coal mine as the research background, Di et al. [12] adopted the methods of engineering analogy, theoretical calculation, and physics simulation to analyze the characteristics of overburden movement and abutment pressure. Based on the D-P criterion, Lode parameter correction statistical calculation formula was introduced to quantitatively analyze the size, location, and range of the abutment pressure peak point. Wang [13] established the strata movement model at the end of the goaf and studied the structural characteristics of the stable front end and the evolution law of lateral support pressure in the goaf. The results show that the fracture of the rock above the solid coal side in the goaf forms a triangular slip zone; with the instability of the fracture in the triangular sliding zone, the lateral support pressure of the solid coal decreases due to the transfer of some loads to the goaf. Based on the engineering and technical problems of the abnormal ground pressure of Datong mining area, Yu et al. [14] established the structural mechanical model of breaking "triangular plate" in the farfield key layer and clarified the relationship between the structural movement of the far-field "triangular plate" and the mine pressure behavior of the working face.

The above scientific research achievements have laid a foundation for exploring the temporal and spatial relationships between the overburden activity and abutment pressure in the goaf under the condition of an extra thick coal seam. However, because of the complexity and particularity of overburden structure and activity law in the goaf of a fully mechanized top coal caving face in the extra thick coal seam, it is necessary that the analysis model is established in order to explore the temporal and spatial evolu- tion laws of lateral abutment pressure in different stages of the overburden activity. It can provide theoretical guidance for the excavation time and layout space of roadway along the goaf.

\section{Engineering Background}

The 8211 working face is located in the second panel of Madaotou coal mine, the north side is the undeveloped solid coal, the south side is the 8210 goaf which has been mined out, and the west side is the panel roadway. The relative position of the 8211 working face is shown in Figure 1. The fully mechanized caving mining method is adopted in the working face. The main mining coal seam is $3-5$, the average dip angle is $2.5^{\circ}$, the average thickness of the coal seam is $15 \mathrm{~m}$, the structure is complex, and the endogenous fractures are developed. There is a multilayer gangue intercalated between the coal seams, with the thickness of $0.7 \mathrm{~m} \sim 3.6 \mathrm{~m}$. The lithology is mainly mudstone, carbonaceous mudstone, and kaolinite mudstone.

The roof of the 8211 working face contains multilayer hard roof with large thickness, good integrity, high strength, and strong compactness. It is basically composed of gray medium coarse sandstone and coarse sandstone. The immediate roof is the interbedding of mudstone and sandstone, the immediate floor is carbonaceous mudstone, and the floor is gray white medium grained sandstone and fine sandstone. The main mineral composition is quartz, feldspar, and calcareous cementation (see Table 1 for the rock properties of 8211 working face).

\section{Stability Evaluation of Surrounding Rock}

Combined with the observation results of roof strata (Figure 2) and physical and mechanical tests of coal samples, the mechanical parameters and properties of the coal and rock are obtained [15]. The uniaxial compressive strength of coal is $11 \mathrm{MPa}$, the uniaxial tensile strength is $1.28 \mathrm{MPa}$, the elastic modulus is $6.16 \mathrm{MPa}$, and the internal friction angle is $15.3^{\circ}$. Coal seam has poor integrity, low strength, and easy breakage, which is not conducive to the roadway surrounding rock control. The uniaxial compressive strength of sandstone is $79.4 \mathrm{MPa}$, the uniaxial tensile strength is $5.83 \mathrm{MPa}$, the elastic modulus is $42.84 \mathrm{MPa}$, and the internal friction angle is $36.26^{\circ}$. Roof sandstone is relatively complete with hard and high strength, which has a huge impact on the working face and roadway below.

\section{Overburden Structure Characteristics of FMTCCM in Extra Thick Coal Seam}

4.1. Structural Form of Overburden. In the process of studying the strata control in mines, it is found that the mine pressure behavior law of stopes and roadways is closely related to the structural form and activity characteristics of overlying strata, especially the key strata that play a decisive role in controlling the strata behaviors of stopes and roadways. According to the "three zones" theory of overlying strata movement, the distribution and location 


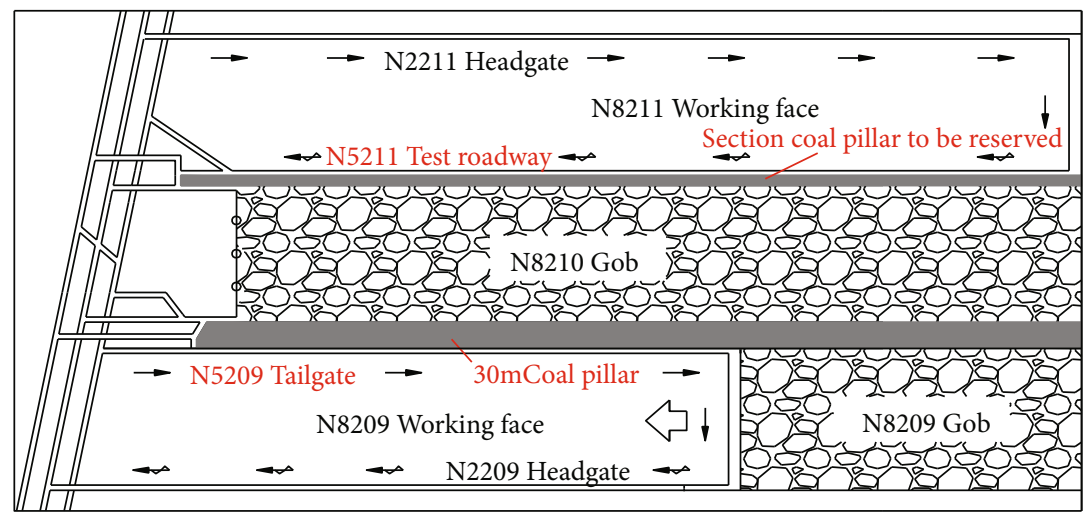

Figure 1: Relative position relationship of the 8211 working face.

TABLE 1: Lithology of the 8211 working face.

\begin{tabular}{|c|c|c|c|}
\hline Lithology & Thickness (m) & Depth $(\mathrm{m})$ & Lithology description \\
\hline $\begin{array}{l}\text { Aluminous mudstone and sandy mudstone } \\
\text { interbedding }\end{array}$ & 28.4 & 332.9 & $\begin{array}{l}\text { The upper part is purple patchy aluminum mudstone, and } \\
\text { the lower part is yellow green sandy mudstone. }\end{array}$ \\
\hline Medium coarse sandstone & 9.2 & 342.1 & $\begin{array}{l}\text { It is grayish white coarse-grained massive structure, with } \\
\text { gravel gradually increasing at the bottom. }\end{array}$ \\
\hline Sandy mudstone and siltstone interbedding & 39.4 & 381.5 & $\begin{array}{l}\text { It is mainly composed of light gray sandy mudstone } \\
\text { and siltstone interbedded with thin layer of clay rock. }\end{array}$ \\
\hline Medium coarse sandstone & 13.5 & 395.0 & $\begin{array}{l}\text { Gray white coarse-grained massive structure intercalated } \\
\text { with thin-layer siltstone. }\end{array}$ \\
\hline Siltstone & 3.2 & 398.2 & $\begin{array}{l}\text { The main mineral composition is quartz and calcareous } \\
\text { cementation. }\end{array}$ \\
\hline Carbonaceous mudstone & 2.3 & 400.5 & Black muddy structure, containing root plant fossils. \\
\hline Coal seam & 15.0 & 415.8 & $\begin{array}{l}\text { It is mainly black and semi dark coal with multilayer } \\
\text { gangue and developed endogenous fractures. }\end{array}$ \\
\hline Carbonaceous mudstone & 5.3 & 421.1 & Black muddy structure, containing root plant fossils. \\
\hline Medium fine sandstone & 14.5 & 435.6 & $\begin{array}{l}\text { Gray medium fine structure, containing a thin layer of silt } \\
\text { and fine sandstone. }\end{array}$ \\
\hline
\end{tabular}

characteristics of bending subsidence zone, fracture zone, and caving zone of overlying strata are mainly affected by the mining height, and the relative position of key strata in "three zones" determines the structural form and movement form [16]. For the conventional working face with general mining height, during the mining process, with the increase of the hanging roof area, the roof gradually breaks. The adjacent broken rock blocks will be hinged and occluded with each other to form a relatively stable articulated structure under the action of horizontal thrust, as shown in Figure 3.

For the mining of the extra thick coal seam, the amount of coal mined out at one time is doubled, resulting in a large space increase in gob. Due to the large space size of the goaf, the broken rock above the coal body can not smoothly touch the gangue. Instead, the cantilever beam structure is located above the coal body. Stable hinged structures can be formed in the key strata of higher layers above the cantilever [17]. The structural form of the key strata is mainly determined by the mining height and the position of the key strata. The occurrence state of the key strata and the activity pattern have a direct impact on the mine pressure behavior of the stope and roadway. Therefore, it is the primary problem to determine the structure of the upper key strata after the lower coal body is mined out.

According to the relevant calculation $[18,19]$, the structural form of the cantilever beam is formed in the lower key strata after the lower coal body is mined out. It can be seen that the overlying strata of FMTCCM in the extra thick coal seam has a structural form of low cantilever beam (LCB) and high hinged rock beam (HHRB). The structural model is shown in Figure 4.

4.2. Mechanical Analysis of Overburden Structure. With the continuous mining of coal, LCB gradually turns and deforms and forms a separation layer with the HHRB, which forces the HHRB structure to lose its support and slide. The unstable hinged rock beam structure acts on the LCB, causing the LCB breaking and further rotation deformation. The movement of the whole "cantilever beam + hinged rock beam" structure is the main factor causing the strong underground pressure behavior of the working face and roadway below. Therefore, it is necessary to carry out mechanical analysis of the whole overburden structure, so as to clarify the relationship between the key overburden structures. 

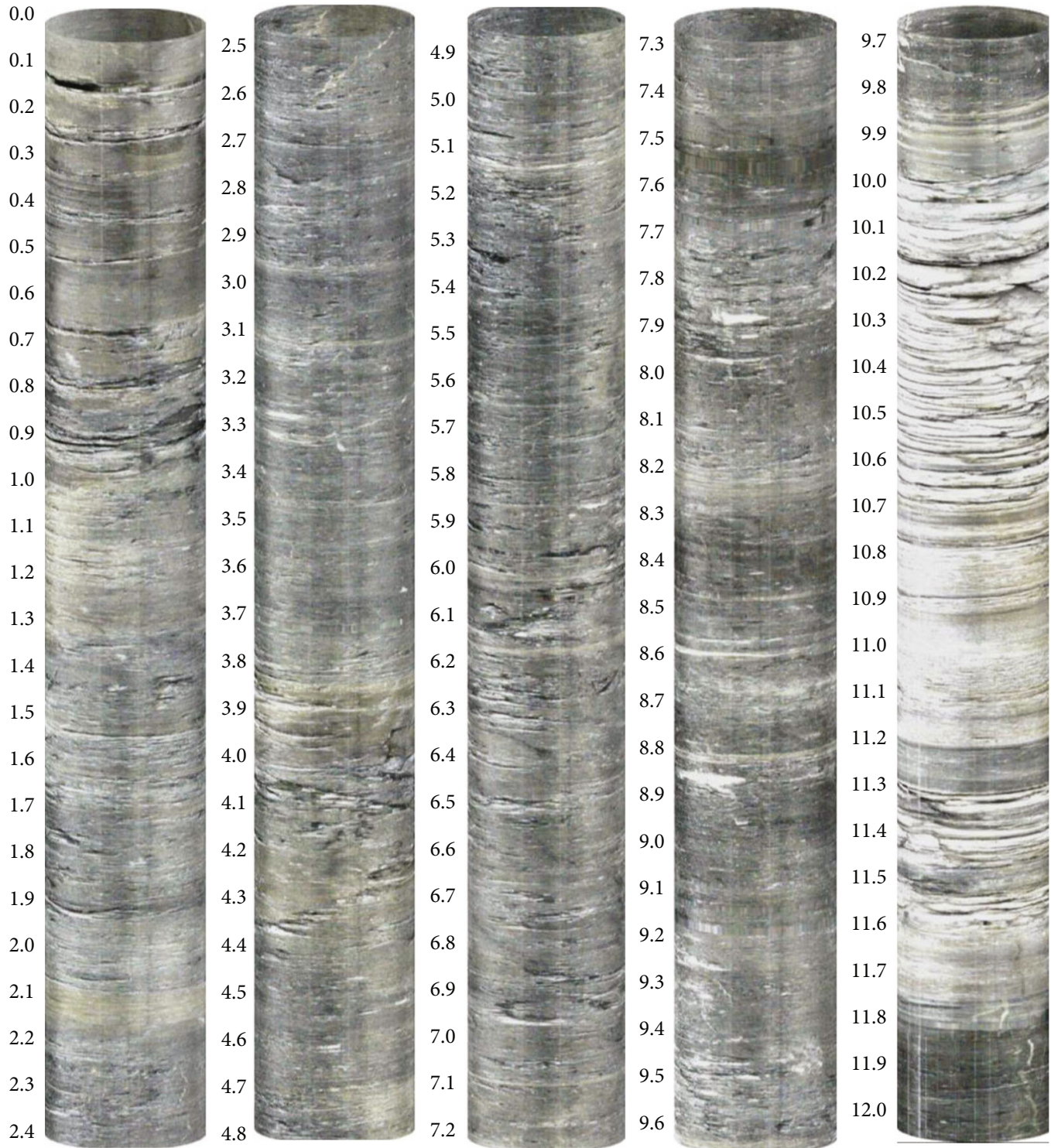

Figure 2: Observation results of roof strata structure.

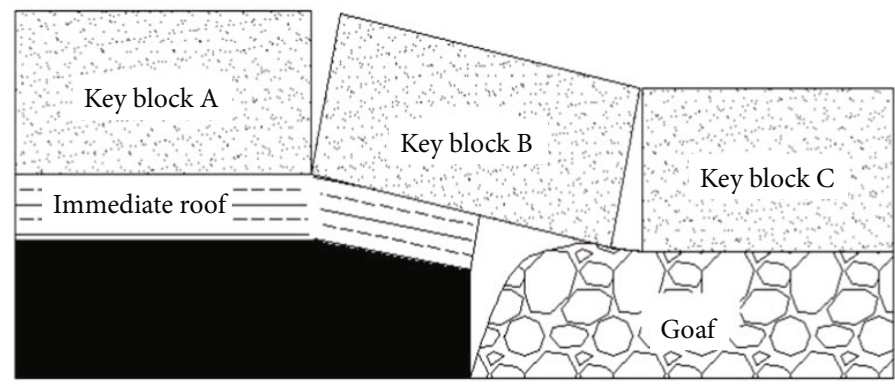

FIgURE 3: Structural characteristics of overburden for the conventional working face.

4.2.1. Mechanical Analysis of Hinged Rock Beam Structure. The mechanical model of hinged rock beam structure is established, and the force of each key block is analyzed. The bearing state of key block $C$ is shown in Figure 5, where the adjacent key blocks are hinged to $\mathrm{O}_{3}$, the hori- zontal thrust between them is $T_{B C}$ and $T_{C D}$, the uniform load of overlying strata is $q_{4}$, the supporting force of caving gangue on key block $B$ is $q_{3}$, the downward force of key block $B$ on key block $C$ is $f_{B C}$, and the weight of key block $C$ is $Q_{C}$. 


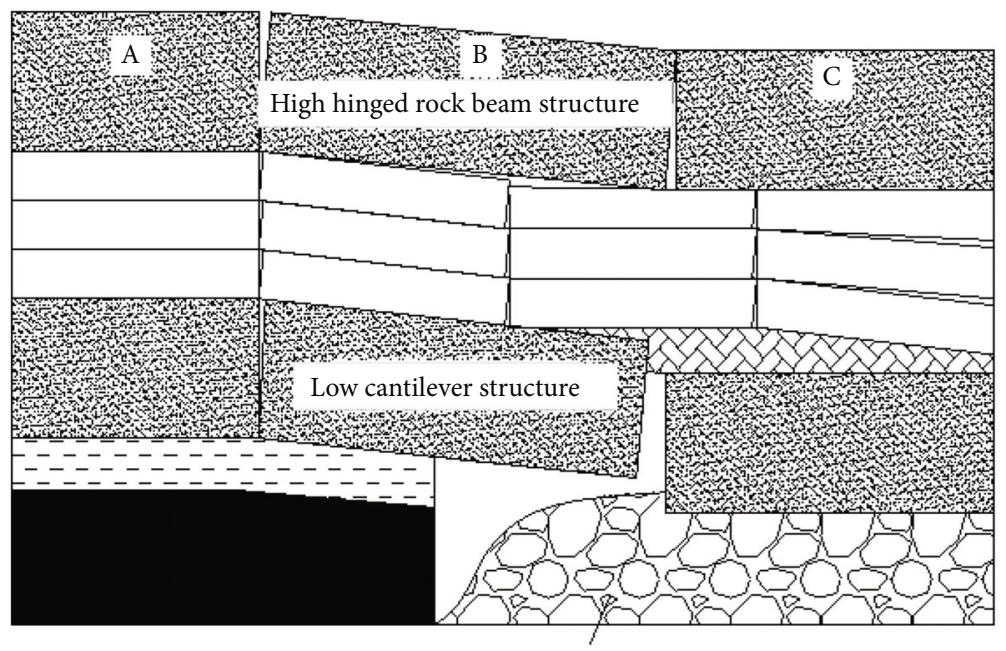

Goaf of 8210 fully mechanized caving face

Figure 4: Overburden structure characteristics.

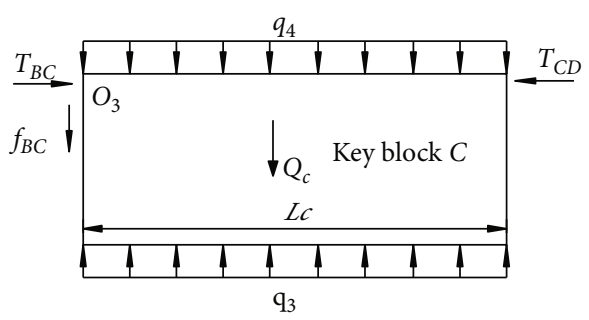

FIGURE 5: Mechanical analysis of key block $C$.

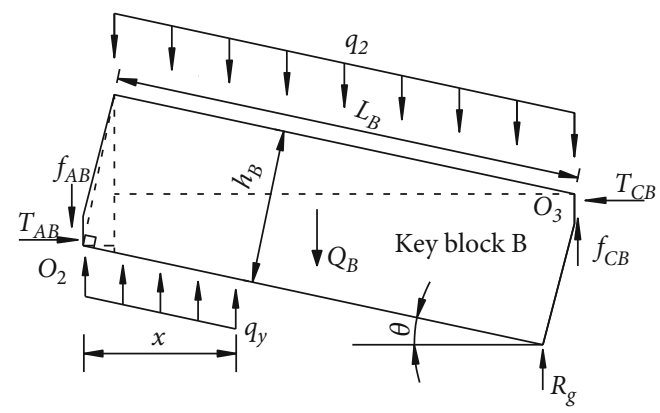

FIgURE 6: Mechanical analysis of key block $B$.

If $\sum x=0$ and $\sum y=0$ in the vertical and horizontal directions, then

$$
\begin{aligned}
& T_{B C}=T_{C D}, \\
& f_{B C}=q_{4} L_{C}-q_{3} L_{C}-Q_{C} .
\end{aligned}
$$

$T_{B C}$ can be obtained by the following formula [20,21]:

$$
T_{B C}=\frac{L_{B}\left(Q_{B}+q_{2} L_{B}\right)}{2 h_{B}-L_{B} \sin \theta},
$$

where the length and thickness of key block $B$ are $L_{B}$ and $h_{B}$, respectively, and the uniform loads imposed on blocks $B$

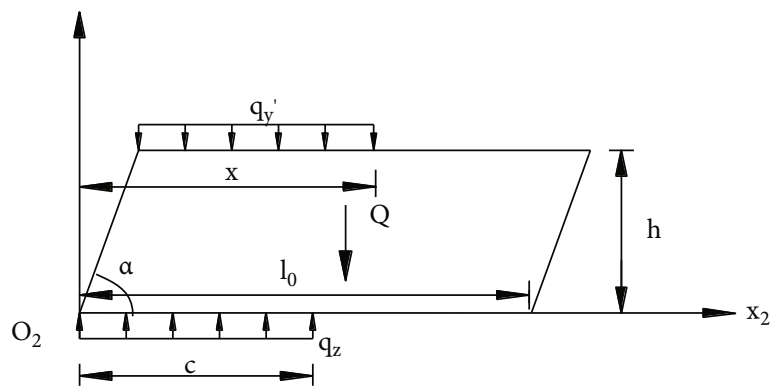

Figure 7: Force analysis of the cantilever beam structure.

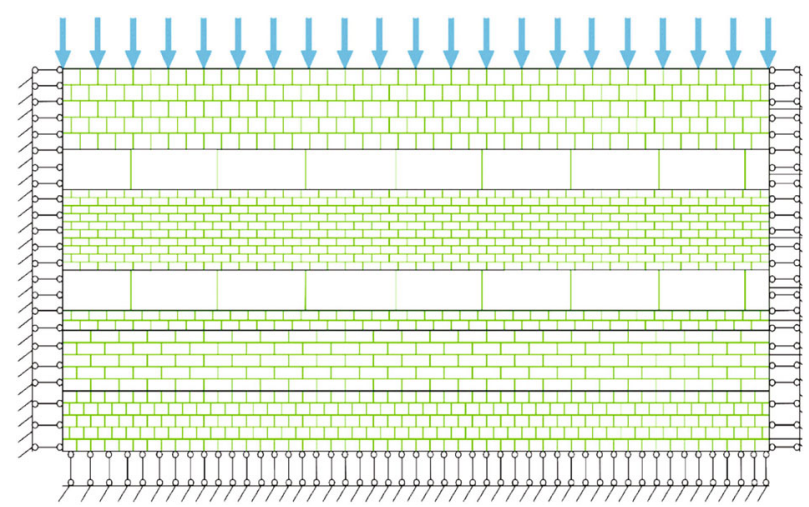

FIgure 8: Numeric calculation model.

and $C$ by the overlying weak rock layer are $q_{2}$ and $q_{4}$, respectively, which can be obtained by controlling the unit weight of the weak rock layer by the key block. The weight of key block $B$ is $Q_{B}$, the rotating angle of key block $B$ is $\theta$, and the breaking distances of key blocks $B$ and $C$ are $L_{B}$ and $L_{C}$, respectively.

Key block $B$ is hinged with key blocks $A$ and $C$ at points $\mathrm{O}_{2}$ and $\mathrm{O}_{3}$, respectively. The bearing state of key block $C$ is shown in Figure 6. Where the supporting force of weak rock stratum on key block $B$ is $q_{\mathrm{y}}$, the length of the supporting 
force is $x$, and the supporting force of goaf gangue on key block is $\mathrm{Rg}$. The vertical forces imposed by key blocks $A$ and $C$ on key block $B$ are $f_{A B}$ and $f_{B C}$, and the both are mutual forces. The horizontal forces imposed by key blocks $A$ and $C$ on key block $B$ are $T_{C B}$ and $T_{A B}$, respectively. Taking $\sum x=0, \sum y=0$, and calculate the moment for $\mathrm{O}_{2}, \sum M$ $\mathrm{O}_{2}=0$, then

$$
q_{y} x^{2}=\left[\begin{array}{c}
q_{2}\left(\frac{L_{B}}{2} \cos \theta+h_{B} \sin \theta\right)+Q_{B} \frac{\left(L_{B} \cos \theta+h_{B} \sin \theta\right)}{2} \\
-T_{C B}\left(h_{B} \cos \theta-L_{B} \sin \theta\right)-f_{C B}\left(L_{B} \cos \theta+h_{B} \sin \theta\right) \\
-R_{g} L_{B} \cos \theta
\end{array}\right] \cos \theta .
$$

4.2.2. Mechanical Analysis of Cantilever Beam Structure. The mechanical model of the cantilever beam structure is established, as shown in Figure 7. For the force analysis of cantilever beam structure, $\sum M \mathrm{O}_{2}=0$, which satisfies the following balance equation:

$$
\frac{1}{2} Q\left(l_{0}+h \cot \alpha\right)+q_{y}^{\prime}\left[x^{2}-(h \cot \alpha)^{2}\right]-q_{z} c^{2}=0,
$$

where the sum of the gravity of the cantilever beam and the strata load controlled by cantilever beam is $Q$; the thickness and fracture distance of the cantilever beam are $h$ and $l_{0}$, respectively; the dip angle of the fracture is $\alpha$; the load under the action of the hinged rock beam structure is $q_{y}{ }^{\prime}$; and the force of the underlying coal and rock mass on the cantilever beam is $q_{\mathrm{z}}$, and the distance from the fracture position of the cantilever beam to $Q_{2}$ is $c$.

Through simultaneous equations (3), (4), and (5), the following $q_{z}$ is obtained.

$$
q_{z}=\left(\frac{1}{c}\right)^{2}\left\{\left[\begin{array}{c}
q_{2}\left(\frac{L_{B}}{2} \cos \theta+h_{B} \sin \theta\right)+Q_{B} \frac{\left(L_{B} \cos \theta+h_{B} \sin \theta\right)}{2} \\
-\frac{L_{B}\left(Q_{B}+q_{2} L_{B}\right)}{2 h_{B}-L_{B} \sin \theta}\left(h_{B} \cos \theta-L_{B} \sin \theta\right) \\
-\left(q_{3} L_{C}-q_{4} L_{C}-Q_{C}\right)\left(L_{B} \cos \theta+h_{B} \sin \theta\right) \\
-R_{g} L_{B} \cos \theta
\end{array}\right] \frac{\cos \theta}{x^{2}}\left[x^{2}-(h \cot \alpha)^{2}\right]+\frac{1}{2} Q\left(l_{0}+h \cot \alpha\right)\right\} .
$$

From the above formula, it can be seen that the stress environment of the coal body near the goaf is closely related to the breaking position of the cantilever beam structure. The bearing capacity of the coal body near goaf is inversely proportional to the square of the breaking position $c$ of the cantilever beam structure.

\section{Movement Characteristics of Overlying Strata Structure}

Considering the overlying strata in the goaf are mostly in discrete state, UDEC numerical simulation software is used to analyze the characteristics of overlying strata structure movement and its correlation with lateral abutment pressure distribution law of coal body [22, 23].

5.1. Establishment of Numerical Calculation Model. Combined with engineering conditions of the 8210 working face in Madaotou coal mine, the numerical model is established (Figure 8). The simulated working face length along the $x$ -axis direction is $300 \mathrm{~m}$. The deformation of the model is constrained by fixed boundary. The horizontal boundary of the model and the vertical direction of the bottom boundary are fixed. The equivalent uniform load of $8.5 \mathrm{MPa}$ is applied at the upper boundary. The coal and rock mechanical parameters are shown in Table 2.
5.2. Overburden Movement along Goaf and Evolution of Lateral Abutment Pressure. During the mining of the upper working face, overlying rock structure undergoes the whole process of deformation, fracture, rotary subsidence, and stability. Combined with numerical analysis results and the internal and external stress field theory [24], the formation and development of lateral abutment pressure can be divided into four stages (Figure 9).

The first stage is before the change of support capacity of the coal wall. At this stage, the key strata in relatively stable state gradually transmit the pressure of overburden to the upper part of the coal seam, and the stress of the coal body has not reached its ultimate bearing strength. Therefore, the whole coal seam, including the side coal wall of the goaf, is in elastic deformation state. The process of abutment pressure is a monotone decline curve with the peak value at the edge of the coal wall, as shown in Figure 9(a).

The second stage is from the beginning of coal abutment pressure changed to the key strata broken. With the increasing of overburden activity, the lateral abutment pressure in a certain range increases to exceed the strength limit of the coal seam. With the destruction of the coal body, its bearing capacity begins to decrease. The process of abutment pressure on the coal seam will divide into the plastic zone and elastic zone. The pressure increases gradually in the plastic zone and decreases monotonically in the elastic zone. The 
TABLE. 2: Joint mechanical parameters of coal and rock.

\begin{tabular}{lccccccc}
\hline Lithology & $\begin{array}{c}\text { Normal stiffness } \\
(\mathrm{GPa})\end{array}$ & $\begin{array}{c}\text { Shear stiffness } \\
(\mathrm{GPa})\end{array}$ & $\begin{array}{c}\text { Shear modulus } \\
(\mathrm{GPa})\end{array}$ & $\begin{array}{c}\text { Bulk modulus Cohesion } \\
(\mathrm{GPa})\end{array}$ & $\begin{array}{c}\text { Internal } \\
\text { friction angle } \\
(\mathrm{MPa})\end{array}$ & $\begin{array}{c}\text { Tensile strength } \\
\left({ }^{\circ}\right)\end{array}$ \\
\hline Overlying strata 2 & 4.1 & 2.3 & 7.1 & 8.1 & 10.5 & 33.3 & 3.2 \\
Medium coarse sandstone & 5.2 & 2.9 & 10.2 & 15.3 & 26.5 & 35.4 & 5.8 \\
Overlying strata 1 & 3.8 & 2.1 & 8.3 & 8.9 & 11.9 & 28.1 & 3.3 \\
Medium coarse sandstone & 5.2 & 2.9 & 10.2 & 15.3 & 26.5 & 35.4 & 5.8 \\
Siltstone & 4.8 & 2.6 & 9.8 & 12.1 & 15.5 & 33.2 & 4.3 \\
Carbonaceous mudstone & 2.6 & 1.4 & 2.8 & 3.6 & 10.8 & 28.1 & 3.8 \\
Coal seam & 2.2 & 1.2 & 1.7 & 2.2 & 5.9 & 15.3 & 1.3 \\
Carbonaceous mudstone & 3.6 & 1.7 & 2.8 & 3.6 & 10.8 & 28.1 & 3.8 \\
Siltstone & 5.6 & 2.8 & 8.2 & 10.3 & 7.2 & 34.8 & 3.7 \\
\hline
\end{tabular}

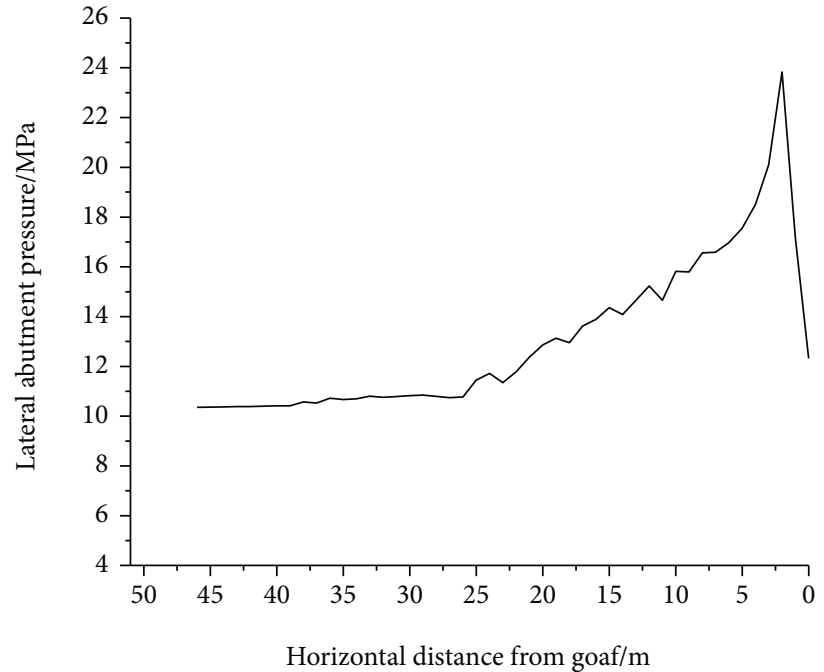

(a) The first stage

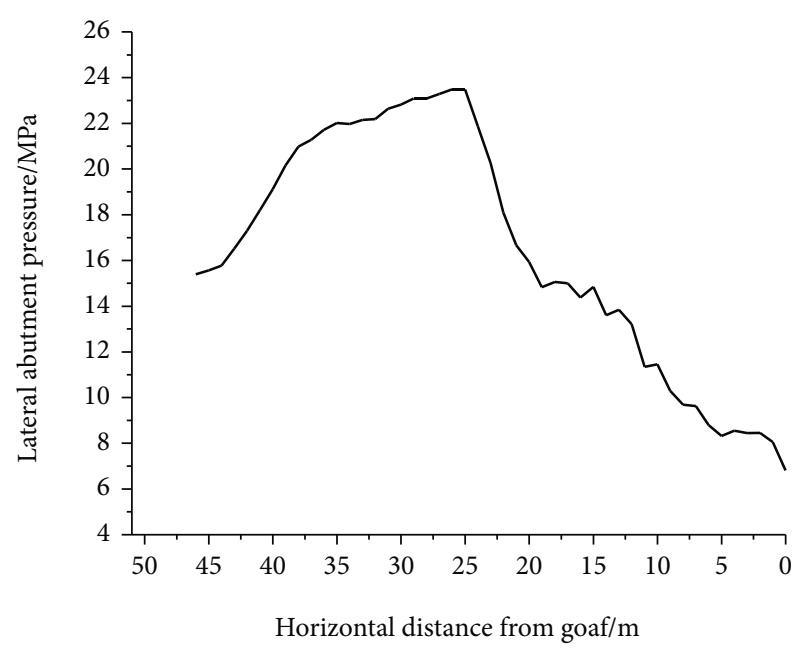

(c) The third stage

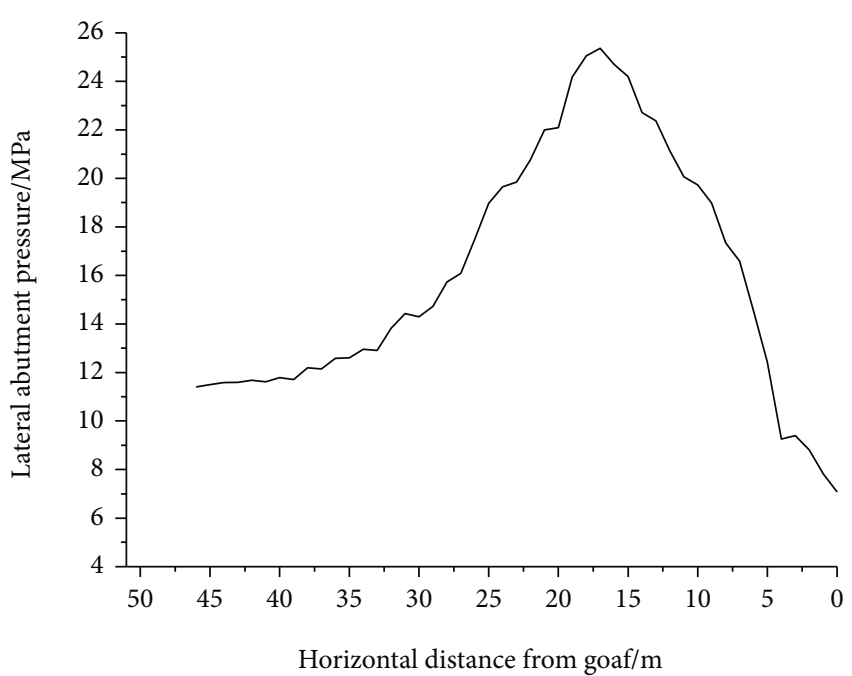

(b) The second stage

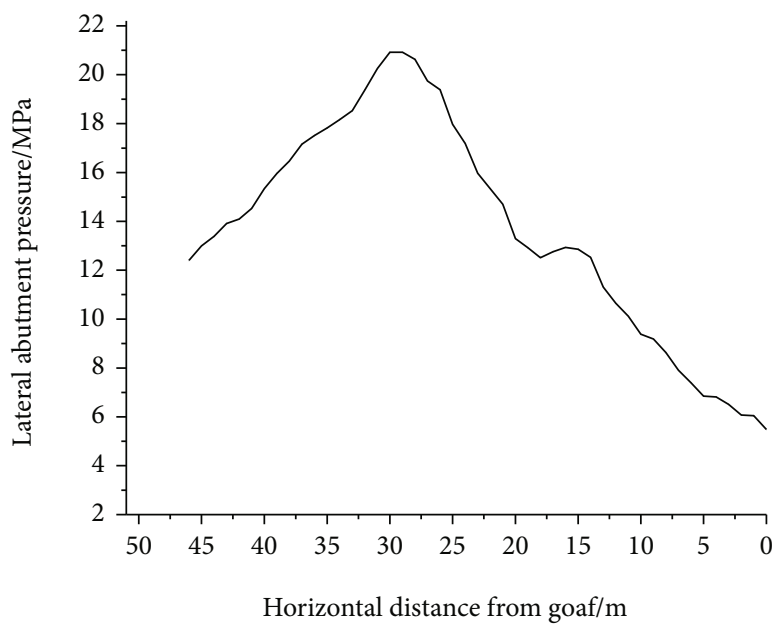

(d) The fourth stage

FIGURE 9: Structural characteristics of overburden movement and dynamic distribution curve of lateral abutment pressure in different stages.

peak position of the pressure is at the junction of the elasticplastic zone, as shown in Figure 9(b).

The third stage is from the key strata broken to touch gangue. Before the key strata are broken, it is in a state of tensile stress concentration near the broken line. When the tensile stress exceeds the tensile strength limit, the strata will break in front of the coal wall on the goaf side. The abutment pressure distribution is clearly divided by the broken line. 
The two parts are the internal stress field controlled by the LCB and HHRB structure located within the broken line, and the external stress field that bears the additional stress of the upper rock layer beyond the broken line, as shown in Figure 9(c).

The fourth stage is from a low-level key stratum and high-level key stratum movement, touch- gangue to stability. At this stage, the overall failure height of overlying strata does not increase any more, the arch height of fracture arch reaches the maximum value, and the relative positions of the internal and external stress fields and stress peaks are basically stable. The lateral coal mass of the goaf is in a relatively stable overburden structure and stress environment, as shown in Figure 9(d).

The average thickness of the coal seam in Madaotou coal mine is $15 \mathrm{~m}$, which belongs to the extra thick coal seam. The overlying strata will go through the movement process described in the above four stages. Because of the large thickness of the coal seam, the huge mining space will be formed, which leads to a violent and long lag period overlying rock activity. The peak value of abutment pressure formed is high, and the influence range is large. At the same time, it will take a long time for the overlying rock movement to reach a stable state. It can be seen that roadway driving along the goaf in the fourth stage, namely, the stable abutment pressure stage, can ensure that the gob side roadway is in a relatively stable overburden structure and stress environment.

\section{Field Measurement}

The lateral abutment pressure is monitored by installing a borehole stress meter on the coal pillar side. Firstly, it can reveal the dynamic evolution law of the coal pillar abutment pressure on the goaf side, which can reflect the movement state of the overlying strata in the goaf, and clarify the activity and stability stage of the overlying strata. Secondly, it can also judge the bearing capacity of different areas in the coal pillar according to the influence range and distribution state of the coal pillar bearing pressure on the goaf side [25].

The borehole stress gauge is installed at the coal pillar side of gob side roadway of the N8209 working face to monitor lateral abutment pressure, so as to verify the broken position of overburden rock and the evolution law of abutment pressure. The layout of monitoring station is shown in Figure 10.

As mentioned above, monitoring the abutment pressure in the coal pillar can reflect the strata movement state in the gob. According to Figure 11, when the working face is mined to about $30 \mathrm{~m}$ behind the station, the abutment pressure with a borehole depth of $13 \mathrm{~m}$ ( $17 \mathrm{~m}$ from the edge of the goaf) has dropped significantly and then slowly rises as the working face continues to advance. It is indicated that overlying strata is fractured near $17 \mathrm{~m}$ from the coal wall edge of the goaf, and the fractured rock masses squeeze the coal in the subsequent rotation process. The abutment pressure stress with a borehole depth of $8 \mathrm{~m}(22 \mathrm{~m}$ from the edge of the goaf) increased significantly and then gradually slowed down and stabilized with the distance of the working face,

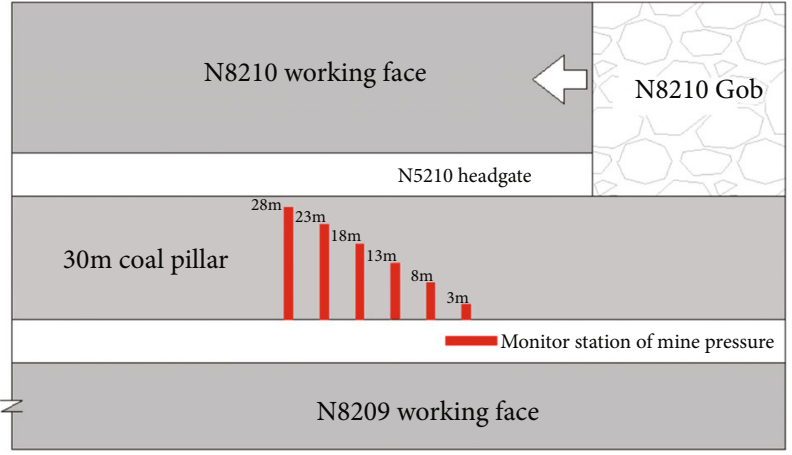

FIgUre 10: The layout of monitoring station.

indicating that the partial load was transferred to the front of fracture position after the rock block is fractured. Compared with a borehole depth of $28 \mathrm{~m}$, the abutment pressure with a borehole depth of $3 \mathrm{~m}$ ( $27 \mathrm{~m}$ from the edge of the goaf) always maintains a higher stress level, and the coal body within this range still has a certain bearing capacity. However, in the mining process of the working face, it becomes a potential deformation and failure area due to strong mining, which is prone to plastic deformation and failure.

The abutment pressure with a borehole depth of $28 \mathrm{~m}$ ( $2 \mathrm{~m}$ from the edge of the goaf) decreased significantly at $30 \mathrm{~m}$ behind the working face. It shows that the coal bearing capacity at the location was reduced, and yield failure occurred, causing the stress to transfer to the depth of the coal pillar. The abutment pressure with borehole depths of $23 \mathrm{~m}$ and $18 \mathrm{~m}$ (7 $\mathrm{m}$ and $12 \mathrm{~m}$ from the goaf, respectively) have a small increase in front of the work face but little change. It indicates that the coal body is still elastic state and has a large bearing capacity within the range of $7 \mathrm{~m} \sim 12 \mathrm{~m}$ from the goaf. From the above discussion, it can be concluded that field measurement results are consistent with theoretical analysis.

The stress distribution law of coal pillar drilling at different positions from the 8210 working face is shown in Figure 12.

(1) With the advance of the working face, the abutment pressure of the coal pillar redistributes during the movement of the overlying strata. Before the overlying strata is broken, the stress curve of the coal pillar presents a "single hump" type, and the peak value of the overall stress is shifted to the side of the roadway along the goaf. After the overlying strata is broken, the stress curve of the coal pillar presents the "asymmetric saddle" type, and the stress value of the coal pillar side in the goaf is smaller than that of the coal pillar side along the roadway, which indicates that the mining roadway under the condition of $30 \mathrm{~m}$ protective coal pillar is always in a high stress environment during the movement of the overlying strata

(2) The coal body within a certain range from the edge of the goaf wall is in a low stress state, and the coal body has a certain bearing capacity. If the mining 

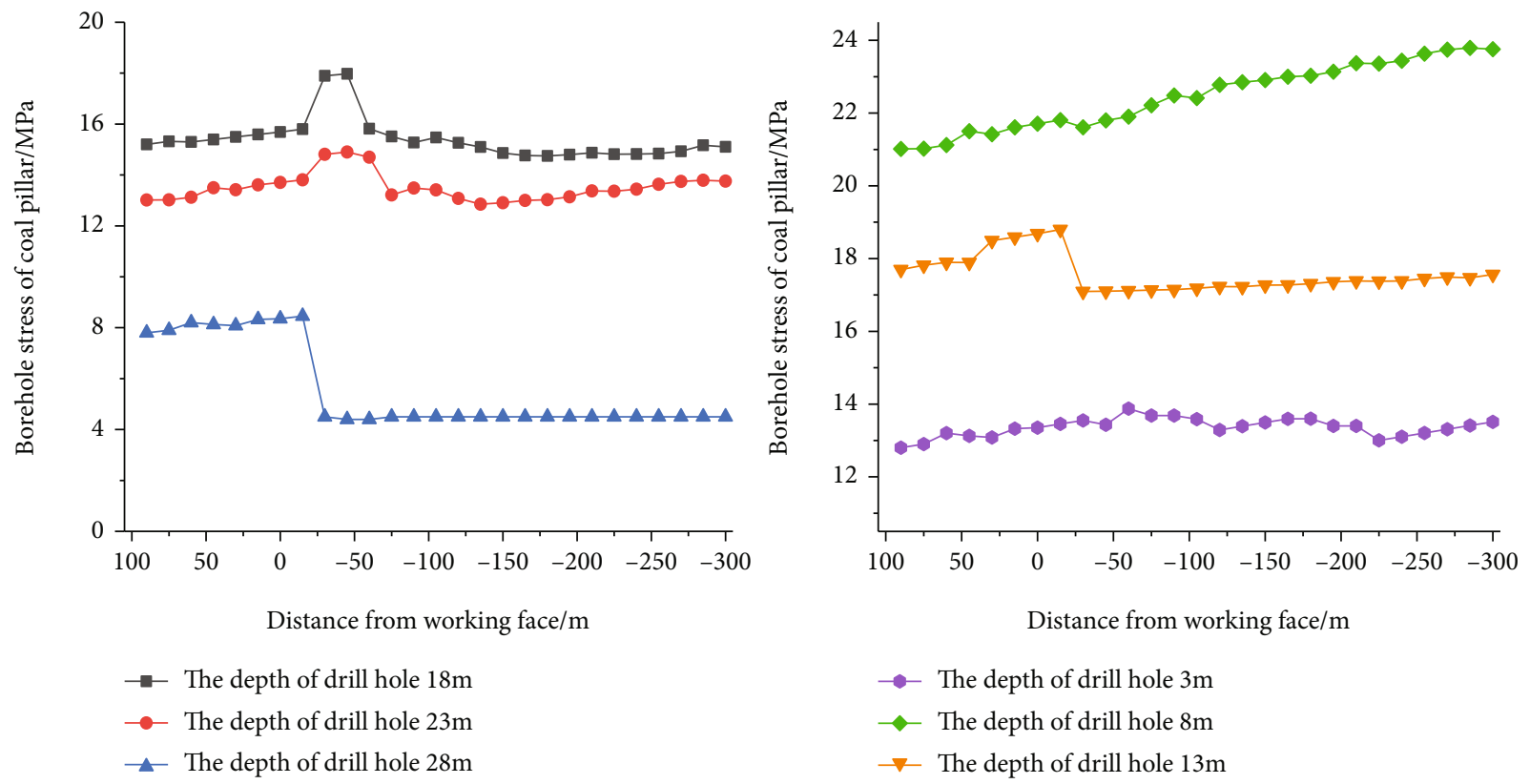

FIGURE 11: Relation between borehole stress of coal pillar and distance from working face.

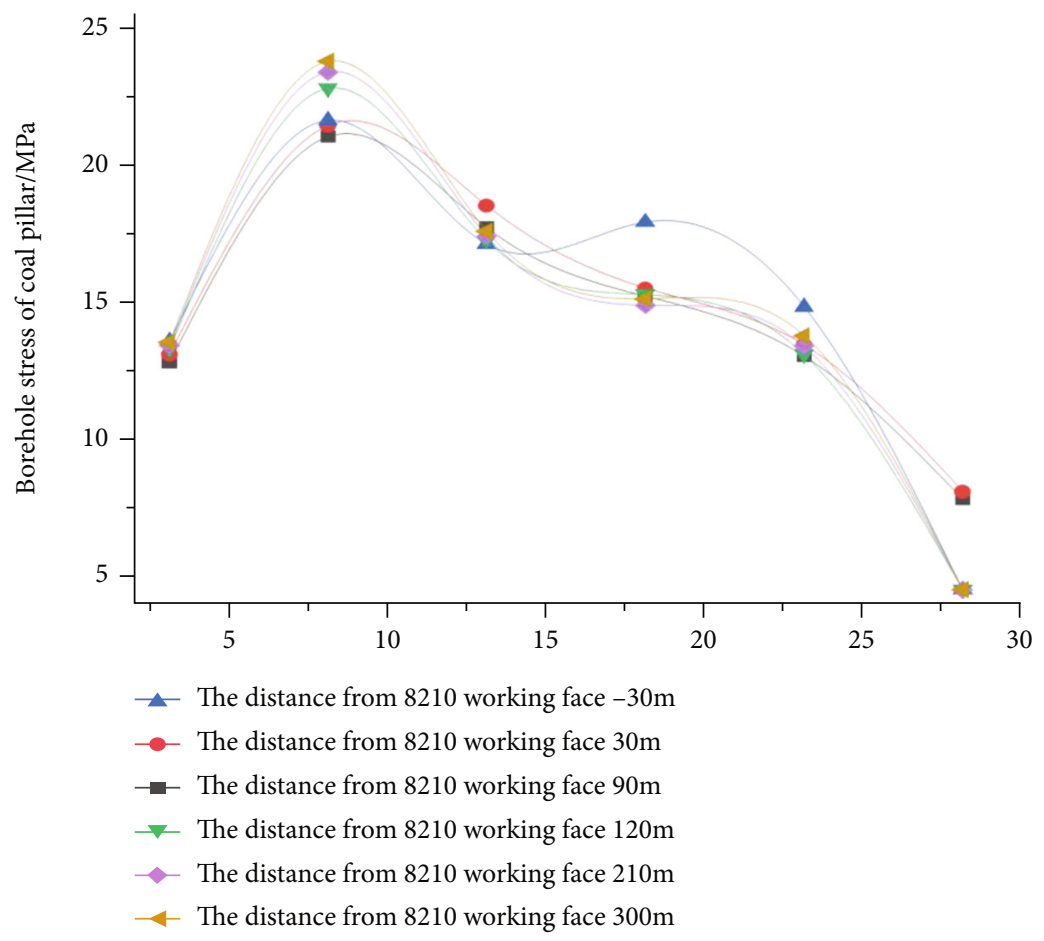

Figure 12: Dynamic evolution of bearing stress in the coal pillar.

roadway is arranged in this area, it is easier to maintain the roadway under the strong mining influence. Within the range of $300 \mathrm{~m}$ behind the working face, the abutment pressure of the coal pillar is always in the state of dynamic adjustment. Until the working face is pushed over $300 \mathrm{~m}$, the abutment pressure in the coal pillar tends to be stable, and the activity of the overlying strata gradually is stopped

\section{Conclusion}

(1) As the coal body is continuously mined, the unstable hinged rock beam structure acts on the low cantilever beam and causes the low cantilever beam to break and further turn to be deformed, which is the main factor causing the strong mine pressure behavior of the working face and roadway below 
(2) Four different movement stages of overlying rock structure along the goaf side of the extra thick coal seam are obtained and analyzed in detail. It is proposed that roadway driving along the goaf in stable abutment stress stage can avoid roadway in unstable overburden structure and stress environment

(3) The fracture position and lateral abutment pressure evolution process of overlying strata on the gob side of the extra thick coal seam are confirmed by field measurement, which provides reference for the reasonable driving time and location of roadway

\section{Data Availability}

The data used to support the findings of this research are included within the paper.

\section{Conflicts of Interest}

The authors declare that there are no conflicts of interest.

\section{Acknowledgments}

This work was supported by The Program of State Key Laboratory of Water Resource Protection and Utilization in Coal Mining (SHGF-16-25). The authors gratefully acknowledge the financial support of the abovementioned agency.

\section{References}

[1] H. Yavuz, "An estimation method for cover pressure reestablishment distance and pressure distribution in the goaf of longwall coal mines," International Journal of Rock Mechanics and Mining Sciences, vol. 41, no. 2, pp. 193-205, 2004.

[2] H. Yan, F. L. He, T. Yang, L. Y. Li, S. B. Zhang, and J. X. Zhang, "The mechanism of bedding separation in roof strata overlying a roadway within a thick coal seam: a case study from the Pingshuo coalfield, China," Engineering Failure Analysis, vol. 62, pp. 75-92, 2016.

[3] J. Wang, S. Yang, W. Wei, J. Zhang, and Z. Song, "Drawing mechanisms for top coal in longwall top coal caving (LTCC): a review of two decades of literature," International Journal of Coal Science \& Technology, 2021.

[4] Z. Song, T. Frühwirt, and H. Konietzky, "Fatigue characteristics of concrete subjected to indirect cyclic tensile loading: insights from deformation behavior, acoustic emissions and ultrasonic wave propagation," Construction Building Material, vol. 302, article 124386, 2021.

[5] Z. Song, Y. Wang, H. Konietzky, and X. Cai, "Mechanical behavior of marble exposed to freeze-thaw-fatigue loading," International Journal of Rock Mechanics and Mining Sciences., vol. 138, article 104648, 2021.

[6] D. R. Zhu, Fracture Law of Basic Roof in Longwall Face and Its Application, China University of mining and technology, Xuzhou, 1987.

[7] Z. Q. Song and Z. D. Cui, "Study on green safe and efficient mining mode and engineering theoretical basis of filling without coal pillar research stone," Journal of China Coal Society, vol. 35, no. 5, pp. 705-708, 2010.
[8] Z. Q. Song, Y. Y. Jiang, and J. K. Liu, "Theory and model of practical mine pressure control," Coal Science and Technology, vol. 2, no. 2, pp. 1-10, 2017.

[9] Y. Yu, J. B. Bai, X. Y. Wang, and L. Y. Zhang, "Control of the surrounding rock of a goaf-side entry driving heading mining face," Sustainability, vol. 12, no. 7, 2020.

[10] Q. H. Ma, Z. P. Guo, and K. G. Fan, "Characteristics of ground pressure behavior and feasibility of roadway driving along goaf in fully mechanized top coal caving face," Mine Pressure and Roof Management, vol. 1997, pp. 153-155, 1997.

[11] S. W. Wang, D. B. Mao, and J. F. Pan, "Experimental study on lateral abutment pressure evolution and microseismic activity in goaf," Journal of China Coal Society, vol. 40, no. 12, pp. 2772-2779, 2015.

[12] S. Di, J. R. Wang, and G. J. Song, “Theoretical study on roof movement and abutment pressure distribution characteristics of fully mechanized mining face with $8.5 \mathrm{~m}$ mining height," Journal of China Coal Society, vol. 42, no. 9, pp. 2254-2261, 2017.

[13] Y. B. Wang, "End structure and lateral abutment pressure evolution mechanism of fully mechanized top coal caving face in extra thick coal seam," Journal of China Coal Society, vol. 42, pp. 30-35, 2017.

[14] B. Yu, Z. Y. Zhang, T. J. Kuang, and J. R. Liu, "Stress changes and deformation monitoring of longwall coal pillars located in weak ground," Rock Mechanics and Rock Engineering, vol. 49, no. 8, pp. 3293-3305, 2016.

[15] Z. Y. Song, H. Konietzky, and M. Herbst, "Bonded-particle model-based simulation of artificial rock subjected to cyclic loading," Acta Geotechnica, vol. 14, no. 4, pp. 955-971, 2019.

[16] M. Shabanimashcool and C. C. Li, "Analytical approaches for studying the stability of laminated roof strata," International Journal of Rock Mechanics and Mining Sciences, vol. 79, pp. 99-108, 2015.

[17] J. F. Ju, J. L. Xu, and Q. X. Wang, "Movement pattern of "cantilever beam" structure in key layer of large mining height stope and its influence on mine pressure," Journal of China Coal Society, vol. 36, no. 12, pp. 2115-2120, 2011.

[18] J. F. Ju and J. L. Xu, "Surface stepped subsidence related to topcoal caving longwall mining of extremely thick coal seam under shallow cover," International Journal of Rock Mechanics \& Mining Sciences, vol. 78, pp. 27-35, 2015.

[19] S. H. Yan, X. W. Yin, and H. J. Xu, "Determination of short cantilever hinged rock beam structure and support working resistance in fully mechanized mining with large mining height," Journal of China Coal Society, vol. 36, no. 11, pp. 1816-1820, 2011.

[20] L. L. Wang, C. W. Zang, and S. Liang, "Mechanical model of roadway roof and analysis of surrounding rock instability mechanism," Coal Technology, vol. 33, no. 12, pp. 47-49, 2014.

[21] D. F. Yang, L. F. Zhang, and M. Chai, "Study on roof breaking law of fully mechanized top coal caving mining in extra thick coal seam based on fracture mechanics," Geotechnical mechanics, vol. 37, no. 7, pp. 2033-2039, 2016.

[22] Y. Z. Feng, H. Lu, and B. Jiao, "Law of mine pressure behavior in $8 \mathrm{~m}$ high-cutting working face based on key strata theory," Coal Engineering, vol. 53, no. 3, pp. 1-5, 2021.

[23] Z. Song, H. Konietzky, and X. Cai, "Modulus degradation of concrete exposed to compressive fatigue loading: insights from lab testing," Structural Engineering and Mechanics, vol. 78, pp. 281-296, 2021. 
[24] S. Y. Dong and W. Z. Li, "Influence analysis of principal stress deflection on fault stability based on theory of internal and external stress fields," Safety in Coal Mines, vol. 52, no. 1, pp. 213-219, 2021.

[25] Y. T. Liu, J. D. Wang, and Z. G. Su, "Technology of delay in solving danger in small pillar roadway of kilometer gas mine," Safety in Coal Mines, vol. 52, no. 8, pp. 102-106, 2021. 